\title{
Zoledronic acid augments the radiosensitivity of cancer cells through perturbing S- and M-phase cyclins and p21 ${ }^{\mathrm{CIP} 1}$ expression
}

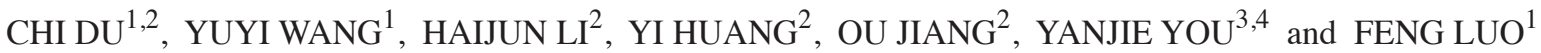 \\ ${ }^{1}$ Department of Medical Oncology, Cancer Center and State Key Laboratory of Biotherapy, West China Hospital \\ of Sichuan University, Chengdu, Sichuan 610004; ${ }^{2}$ Department of Oncology, The Second People's Hospital of Neijiang, \\ Luzhou Medical College, Neijiang, Sichuan 641003; ${ }^{3}$ Pathological Examinations and Research Center; \\ ${ }^{4}$ Department of Pharmacy, Luohe Medical College, Luohe, Henan 462002, P.R. China
}

Received October 18, 2015; Accepted June 2, 2017

DOI: $10.3892 / \mathrm{ol} .2017 .6710$

\begin{abstract}
Radiotherapy and adjuvant chemotherapy have become the standard treatments for multiple types of cancer. Although cancer cells are usually sensitive to radiotherapy, metastasis and local failure still occur mainly due to developed resistance to radiotherapy. Thus, it is critical to improve therapeutics for cancer treatment. The present study demonstrated that third-generation bisphosphonate zoledronic acid (ZOL), even at a low concentration, augments the radiosensitivity of cancer cells exposed to ionizing radiation (IR) by inducing S-phase arrest and subsequently promoting apoptosis. This function of ZOL was associated with elevated levels of cyclin $\mathrm{A}$ and cyclin $\mathrm{B}$ in the $\mathrm{S}$ and $\mathrm{M}$ phases, as well as decreased p $21^{\mathrm{CIP} 1}$ expression. In addition, ZOL also inhibited malignant the invasiveness of cancer cells. Notably, these effects could be enhanced concurrently with IR. The present data indicated that combined treatment with ZOL plus IR may be a novel technique to augment the radiosensitivity of cancer cells.
\end{abstract}

\section{Introduction}

Radiotherapy and adjuvant chemotherapy have become the standard treatments for multiple types of cancer, including esophageal and nasopharyngeal carcinoma $(1,2)$. Although radiotherapy is widely used to treat early-stage tumors, patients with advanced-stage tumors often experience failure of

Correspondence to: Professor Feng Luo, Department of Medical Oncology, Cancer Center and State Key Laboratory of Biotherapy, West China Hospital of Sichuan University, 37 Guoxuexiang Street, Chengdu, Sichuan 610004, P.R. China

E-mail: luofeng@medmail.com.cn

Dr Yanjie You, Pathological Examinations and Research Center, Luohe Medical College, 148 Daxue Road, Luohe, Henan 462002, P.R. China

E-mail: youyanjie@163.com

Key words: radioresistance, zoledronic acid, radiosensitizing effects treatment mainly due to resistance to radiotherapy, resulting in recurrence and distant metastases (2-6). Therefore, the development of potent and reliable radiosensitizers is necessary for improving overall treatment outcomes in cancer therapy.

Zoledronic acid (ZOL) is a compound containing nitrogen and bisphosphonates, which harbors anti-reabsorption effects (7). ZOL is used as therapy for bone metastasis in malignancy and a number of metabolic disorders, including bone pain, bone fractures and hypercalcaemia $(8,9)$. ZOL inhibits farnesyl pyrophosphate synthase, a key enzyme in the isoprenoid biosynthetic pathway, and prevents prenylation of small guanosine triphosphate-binding proteins, including Rho, p21 ${ }^{\text {ras }}$, cell division cycle 42 , Rac and Rab, which are essential for different cellular functions such as signal transduction and cell adhesion (7-9). ZOL is considered to possess antitumor activity, particularly in combination with chemotherapeutic anticancer drugs (10-12). This effect of ZOL could be observed on cancer cells derived from a variety of tumors, including breast, prostate and pancreatic cancers, by inducing cell apoptosis and inhibiting cell invasion, adhesion and angiogenesis (10-13). Currently, numerous patients with bone metastases secondary to a broad range of solid tumors are benefiting from the antitumor effects of ZOL (14).

Our previous study demonstrated the synergistic cytotoxic effects of ZOL and ionizing radiation (IR) on esophageal squamous cell carcinoma and endothelial cells (15). Accordingly, combined treatment with ZOL plus IR may be an encouraging method to treat cancer with less side effects and complications, compared with the use of these agents alone (15-20). However, the molecular mechanism of the radiosensitizing ability of ZOL in cancer cells remains mostly unknown. In the present study, ZOL was revealed to enhance the sensitivity of cancer cells to IR by inducing S-phase arrest in the cell cycle and subsequently promoting apoptosis, which may be due to elevated levels of cyclin A and cyclin B in the S and M phases, as well as decreased expression of the cyclin-dependent kinase inhibitor $\mathrm{p} 21^{\mathrm{CIP} 1}$.

\section{Materials and methods}

Cell culture and reagents. Cancer cell lines (HNE-1 and CNE-2) were gifted from Miss Jiongyu Chen (Cancer Hospital 
of Shantou University Medical College, Shantou, China) and cultured as described previously (21). The above two cell lines are identified as mixed cancer types $(22,23)$. ZOL was kindly supplied by Novartis Pharma AG (Basel, Switzerland) and diluted in $0.9 \%$ saline at a concentration of $10 \mathrm{mM}$ as stock. Aliquots were stored at $-20^{\circ} \mathrm{C}$ and added to the Dulbecco's modified Eagle's medium (DMEM; Gibco; Thermo Fisher Scientific, Inc., Waltham, MA, USA) immediately prior to use.

Cell viability assay. An MTT colorimetric assay was used to measure the proliferation rate of tumor cells treated with ZOL as described previously $(13,19)$. Briefly, cells were plated in triplicate at a density of $4 \times 10^{3}$ cells per well on 96-well plates (Corning Costar, Cambridge, MA, USA), After $24 \mathrm{~h}$ of culture at $37^{\circ} \mathrm{C}$, cells were incubated with $\mathrm{ZOL}$ at various concentrations $(2-32 \mu \mathrm{M})$ at $37^{\circ} \mathrm{C}$ for 48 or $72 \mathrm{~h}$, followed by MTT assays. The purple formazan in each well was dissolved in dimethyl sulfoxide and measured at $490 \mathrm{~nm}$.

Colony formation assay. A colony formation assay was performed as previously described (15). Cells were seeded on 6-well plates at various cell densities $(100,200,400,600$, 800 cells/well) and allowed to grow at $37^{\circ} \mathrm{C}$ for $12 \mathrm{~h}$. Cells were then pretreated with ZOL $(2 \mu \mathrm{M})$ for $6 \mathrm{~h}$ followed by transient exposure to increased doses of irradiation (2-6 Gy, $1 \mathrm{~Gy} / \mathrm{min}$ ) generated by the Gammacell 3000 Elan system (MDS Nordion, Inc., Kanata, ON, Canada). At 24 h after radiation exposure, the medium was replaced with ZOL-free DMEM (Gibco; Thermo Fisher Scientific, Inc.) and cells were cultured at $37^{\circ} \mathrm{C}$ for $12-14$ days. Cellular colonies were formed and were stained with $0.5 \%$ crystal violet (Sigma-Aldrich; Merck KGaA, Darmstadt, Germany) at $37^{\circ} \mathrm{C}$ for $5 \mathrm{~min}$. Cellular colonies were counted under a phase-contrast microscope (magnification, x 100; Carl Zeiss, Thornwood, NY, USA) if $>50$ cells were in a single colony. The surviving fraction (SF) of each plate under different radiation dosages was calculated by dividing the number of cellular colonies by the number of cells plated, and was normalized to the SF of cells without radiation treatment.

Cell cycle analysis. Flow cytometry was used to analyze the cell cycle distribution when cells were pretreated with ZOL $(2 \mu \mathrm{M})$ for $12 \mathrm{~h}$ and then exposed to a single IR dose (4 Gy) for $6 \mathrm{~h}$. Media were replaced the next day, and cells were harvested at $500 \mathrm{x} \mathrm{g}$ for $15 \mathrm{~min}$ at $4^{\circ} \mathrm{C}$ and fixed in $70 \%$ ethanol overnight at $-20^{\circ} \mathrm{C}$. Cells were resuspended and incubated with $500 \mu \mathrm{l}$ of a solution containing $10 \mu \mathrm{g} / \mathrm{ml}$ propidium iodide (PI), $100 \mu \mathrm{g} / \mathrm{ml}$ RNase (Sigma-Aldrich; Merck KGaA) and $20 \mathrm{mM}$ EDTA at $37^{\circ} \mathrm{C}$ for $1 \mathrm{~h}$, followed by cytometric flow analysis. DNA content and the percentages of cells in each cell cycle phase were measured by FACSCalibur (BD Biosciences, Franklin Lakes, NJ, USA).

Cell invasion assay. This procedure has been described previously $(15,21)$. Briefly, cells were pretreated with $2 \mu \mathrm{M}$ ZOL and then plated in 24-well Matrigel-coated Transwell inserts (EMD Millipore, Billerica, MA, USA) at $5 \times 10^{4}$ cells per $500 \mu 1$ of serum-free Dulbecco's modified Eagle's medium (Gibco; Thermo Fisher Scientific, Inc.). The bottom chamber of the Transwell insert was filled with $750 \mu \mathrm{l}$ of DMEM with
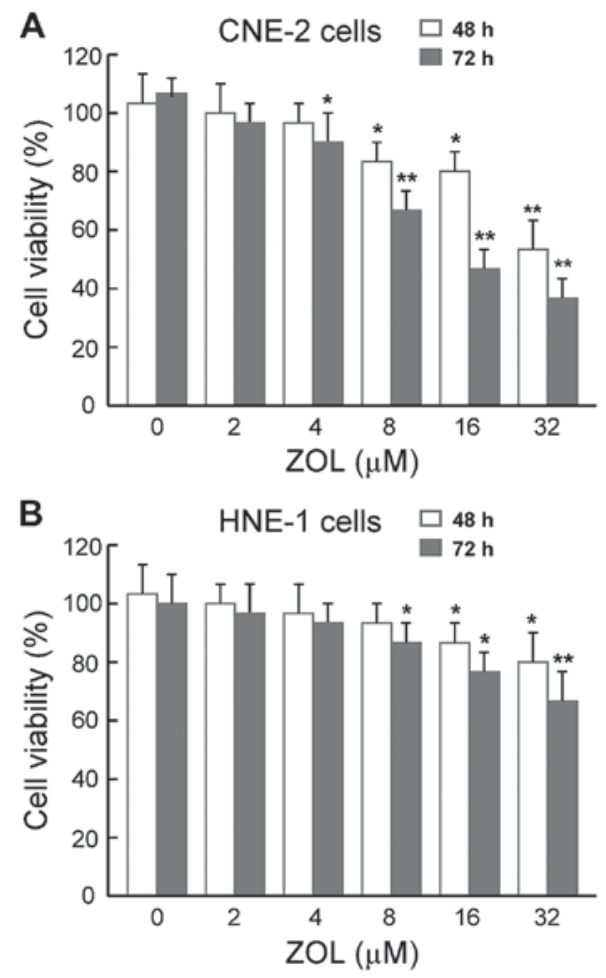

Figure 1. ZOL affects the cell proliferation of (A) CNE-2 and (B) HNE-1 cells in a dose-dependent manner. PBS (vehicle control) or ZOL $(2-32 \mu \mathrm{M})$ was added to the cell culture medium for 48 or $72 \mathrm{~h}$. MTT assay was used to evaluate the cell viability. The experiments were repeated three times. ${ }^{*} \mathrm{P}<0.05,{ }^{* *} \mathrm{P}<0.01$ compared with the vehicle control group. ZOL, zoledronic acid.

10\% fetal bovine serum (Gibco; Thermo Fisher Scientific, Inc.). Irradiation (4 Gy) was immediately applied to cells. Crystal violet (4\%) was used to stain the migrated cells for $15 \mathrm{~min}$ at room temperature, which were then counted using an inverted microscope at x100 magnification. Invasion activity was assessed by the mean number of migrated cells in three microscopic fields, selected randomly.

Western blot analysis. Western blot analysis was performed as described previously $(15,21,24)$. The cells were lysed using radioimmunoprecipitation assay lysis buffer (Tiangen Biotech Co., Ltd., Beijing, China) and $\sim 50 \mu \mathrm{g}$ of total protein from each sample was separated by $12 \%$ SDS-PAGE, followed by transfer to a polyvinylidene difluoride membrane (EMD Millipore). The membrane was blocked overnight at $4^{\circ} \mathrm{C}$ using $5 \%$ bovine serum albumin (Sigma-Aldrich; Merck Millipore) in PBS. The membrane was then incubated with the following primary antibodies overnight at $4^{\circ} \mathrm{C}$ : Rabbit polyclonal antibodies against cyclin A (cat. no. sc-751; dilution, 1:400; Santa Cruz Biotechnology, Inc., Dallas, TX, USA), cyclin B (cat. no. sc-25764; dilution, 1:500; Santa Cruz Biotechnology, Inc.), cyclin D1 (cat. no. sc-717; dilution, 1:200; Santa Cruz Biotechnology, Inc.) and cyclin E (cat. no. sc-717; dilution, 1:200; Santa Cruz Biotechnology, Inc.), and mouse monoclonal antibodies against p21 ${ }^{\mathrm{CIP1}}$ (cat. no. sc-717; dilution, 1:200; Santa

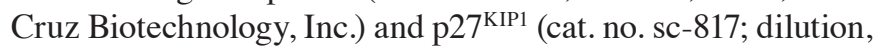
1:500; Santa Cruz Biotechnology, Inc.). Subsequent to washing with $0.1 \%$ Tween-20 in PBS, the membranes were then incubated with the following horseradish peroxidase-conjugated 

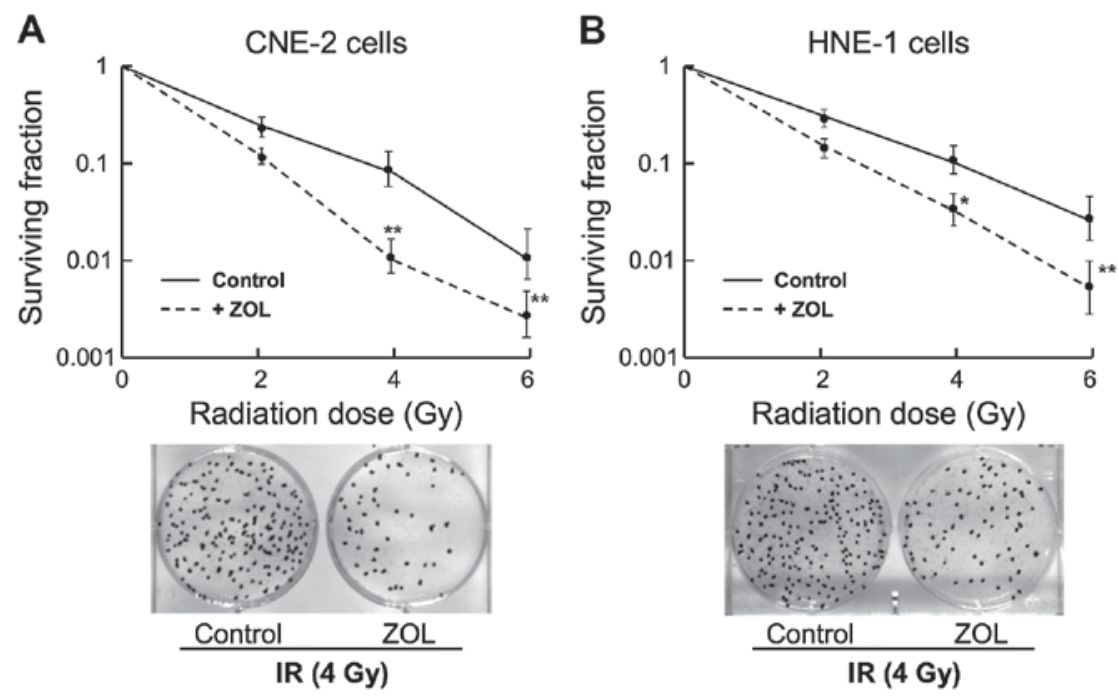

Figure 2. ZOL inhibits clonogenic survival synergistically with IR in (A) CNE-2 and (B) HNE-1 cells. Cells were pretreated with vehicle control or $2 \mu \mathrm{M}$ of ZOL for $6 \mathrm{~h}$ prior to exposure to IR at the indicated doses. The medium was changed the next day and the cells were subsequently incubated in normoxic conditions for 12-14 days prior to staining. Cell colonies were stained and counted, and the relative surviving fraction was calculated. Data are presented as the mean \pm standard deviation of three independent experiments. ${ }^{*} \mathrm{P}<0.05,{ }^{* *} \mathrm{P}<0.01$ compared with the control group. ZOL, zoledronic acid; IR, ionizing radiation.

secondary antibodies for $1 \mathrm{~h}$ at $37^{\circ} \mathrm{C}$ : Goat anti-rabbit immunoglobulin G (IgG; cat. no. sc-2004; dilution, 1:2,000; Santa Cruz Biotechnology, Inc.) and rabbit anti-mouse $\operatorname{IgG}$ (cat. no. sc-358914; dilution, 1:2,000; Santa Cruz Biotechnology, Inc.). Proteins were detected using an enhanced chemiluminescence kit (GE Healthcare Life Sciences, Chalfont, UK). Anti-GAPDH monoclonal antibody (cat. no. ab9485; dilution, 1:2,500; Abcam, Cambridge, MA, USA) was used to assure equal loading of protein.

Statistical analysis. Statistical analysis was performed using the SPSS statistical software package (version 17.0; SPSS Inc., Chicago, IL, USA). Data from at least three independent experiments are presented as the mean \pm standard deviation. Data were analyzed using a paired t-test with Bonferroni adjustment or one-way analysis of variance (ANOVA), followed by the Student-Newman-Keuls post-test for multiple comparisons. $\mathrm{P}<0.05$ was considered to indicate a statistically significant difference.

\section{Results}

ZOL induces anti-proliferative effects on cancer cells. The MTT cytotoxicity assays demonstrated that ZOL decreased the viability of the two cancer cell lines in a dose-dependent manner, either after 48 or $72 \mathrm{~h}$ of treatment (Fig. 1). Notably, the anti-proliferative effects of ZOL on different cell lines were slightly different, with HNE-1 cells being less sensitive to the ZOL compared with CNE-2 cells. These data indicated that different cellular responses to ZOL depend on the intrinsic sensitivity of each cell line.

ZOL enhances IR-induced clonogenic inhibition. Analyses of clonogenicity were then performed to evaluate the quantities of living cellular clones following co-treatment of ZOL plus IR. For all subsequent studies, a relatively low dose of ZOL at $2 \mu \mathrm{M}$ was applied to cells as pretreatment prior to IR exposure.

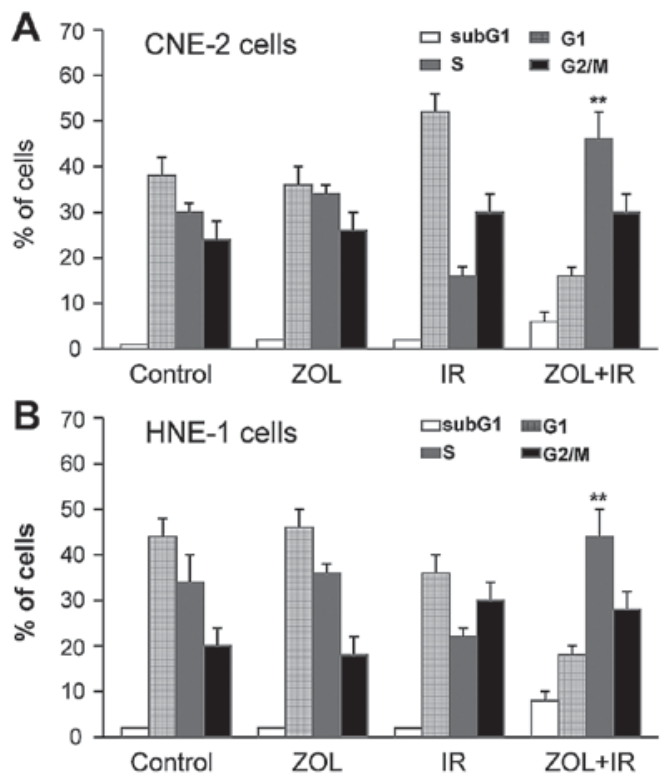

Figure 3. Effects of ZOL and IR on cell cycle distribution. (A) CNE-2 and (B) HNE-1 cells were pretreated with $2 \mu \mathrm{M}$ of ZOL for $6 \mathrm{~h}$, and then irradiated at $4 \mathrm{~Gy}$. The medium was changed the next day. Cell cycle distribution was measured by flow cytometry at $24 \mathrm{~h}$ post-irradiation. ${ }^{* *} \mathrm{P}<0.01$ compared with the control group. ZOL, zoledronic acid; IR, ionizing radiation.

As shown in Fig. 2, combined treatment of CNE-2 and HNE-1 cells with ZOL plus IR significantly inhibited the growth of clonogenic cells as compared with that caused by IR treatment alone.

ZOL triggers cell cycle accumulation in S phase. Flow cytometry was then used to determine whether the anti-proliferative effects of ZOL plus IR were associated with cell cycle distribution changes. As shown in Fig. 3, no significant alteration of the cell cycle was observed in CNE-2 or HNE-1 cells treated with ZOL alone. However, co-treatment with ZOL $(2 \mu \mathrm{M})$ plus IR (4 Gy) resulted in significantly increased S-phase cell 
CNE-2 cells

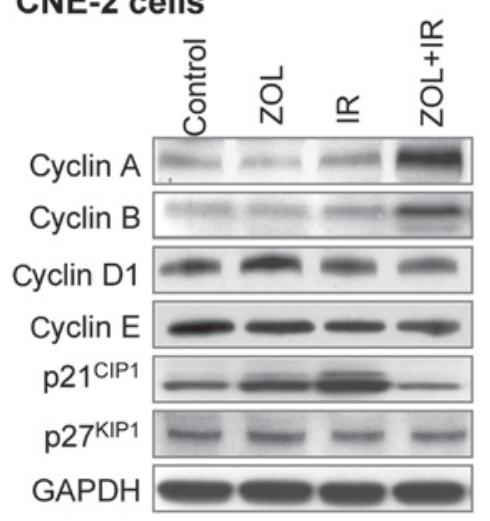

HNE-1 cells

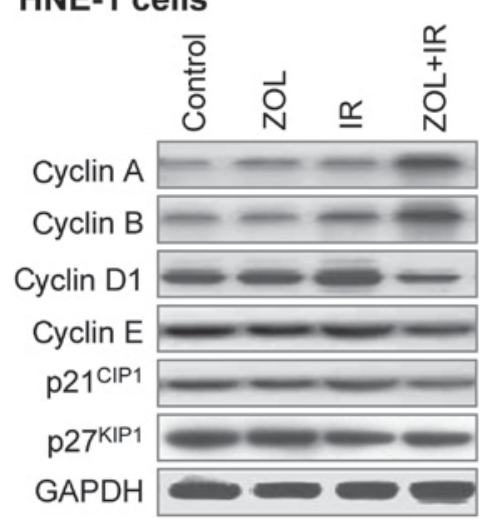

Figure 4. ZOL increases the protein levels of cyclin A and cyclin B, and decreases $21^{\mathrm{CIP1}}$ expression. CNE-2 and HNE-1 cells were treated with $2 \mu \mathrm{M}$ of ZOL for $6 \mathrm{~h}$, and then irradiated at $4-\mathrm{Gy}$ single fractions. Western blot analysis was performed following IR for $24 \mathrm{~h}$ using antibodies against the indicated proteins. ZOL, zoledronic acid; IR, ionizing radiation.

proportions $(\mathrm{P}<0.01)$. In addition, subG1-phase cell proportions were slightly higher in the two cell lines following co-treatment with ZOL plus IR, compared with ZOL or IR treatment alone.

ZOL plus IR elevates the expression levels of S- and M-phase cyclins. According to previous studies, it is controversial whether ZOL affects cyclin and cyclin-dependent kinase inhibitor expression levels in cancer cells (14,25-27). To elucidate the mechanism by which ZOL causes S-phase arrest in CNE-2 and HNE-1 cells, the expression status of cyclins A, B, D1 and $\mathrm{E}$, as well as $\mathrm{p} 21^{\mathrm{CIP1}}$ and $\mathrm{p} 27^{\mathrm{KIP} 1}$, was examined by western blot analysis (Fig. 4). Although there was a slight increase in p21 ${ }^{\mathrm{CIP}}$ protein levels, treatment with ZOL $(2 \mu \mathrm{M})$ or IR (4 Gy) alone exhibited a limited effect on expression patterns. By comparison, the combined treatment led to an increase in cyclin $\mathrm{A}$ and $\mathrm{B}$, with a concomitant faint decrease in cyclins D1 and E. In addition, a decreased level of $\mathrm{p} 21^{\mathrm{CIP}}$ protein was observed, while $\mathrm{p} 27^{\mathrm{KIP1}}$ expression was generally unaltered.

ZOL plus IR results in significant anti-metastatic effects on cancer cells. Our previous study reported that ZOL may impair cancer cell migration and invasion via downregulating vascular endothelial growth factor and matrix metalloproteinase expression (28). Therefore, the aim of the present study was to examine whether this anti-metastatic effect could be

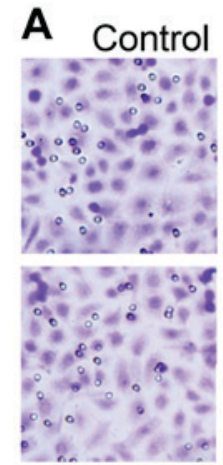

IR CNE-2 cells

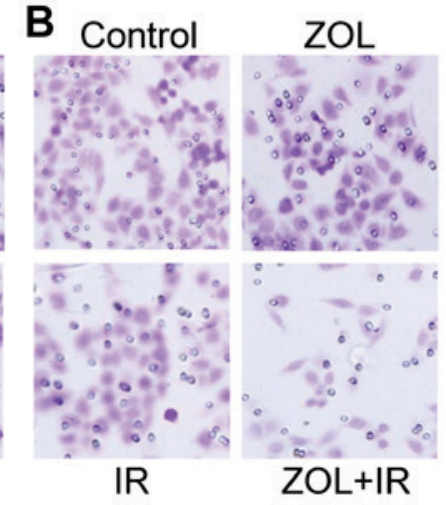

HNE-1 cells

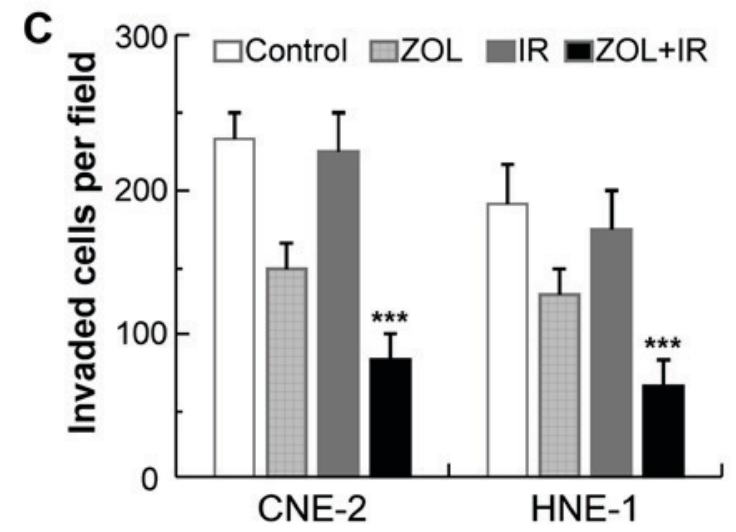

Figure 5. ZOL decreases the mobility and invasiveness of cancer cells. These effects were more significant when combined with IR. (A) CNE-2 and (B) HNE-1 cells were treated with $2 \mu \mathrm{M}$ of ZOL $24 \mathrm{~h}$ after plating and then irradiated at 4 Gy $6 \mathrm{~h}$ later. Cells were subjected to invasion assays. Representative fields (magnification, x100) of invaded cells are shown. (C) Quantitative analysis from three independent experiments. Data are presented as the mean \pm standard deviation. ${ }^{* * *} \mathrm{P}<0.001$ compared with the control. ZOL, zoledronic acid; IR, ionizing radiation.

augmented by co-treatment with ZOL plus IR. Invasion assays were performed on CNE-2 and HNE-1 cells treated with ZOL plus/or IR. ZOL treatment $(2 \mu \mathrm{M})$ significantly decreased the number of invaded cells on the membrane coated with Matrigel in the chambers, as compared with that of the control (Fig. 5). As expected, the anti-metastatic effects of ZOL were enhanced markedly when combined with IR, whereas IR treatment alone had marginal effects. These data suggested that the anti-metastatic effects caused by ZOL and IR were synergistic, which indicates that the effects induced by the combination of ZOL and IR are greater than the sum of the effects caused by ZOL and IR individually.

\section{Discussion}

Resistance to chemotherapeutics and radioactive rays remain the major factors for clinical cancer therapy (3-5). Therefore, it is important to identify reliable radiosensitizers that can increase the sensitivity of cancer cells to IR. Accumulated evidence has revealed that prolonged cell cycle progression with increased susceptibility to apoptosis and Ras signaling inhibition in tumor cells may contribute to the cellular mechanisms of ZOL as a radiosensitizer (17-20). These results demonstrate the possibility that the radiosensitizing effects 
of ZOL and its direct antitumor effects are valuable characteristics for therapeutic interventions in cancer. In the present study, a significant synergistic antitumor effect induced by combination of ZOL plus IR was documented in cancer cells, at least in part through upregulating S- and M-phase cyclins and decreasing p $21^{\mathrm{CIP} 1}$ levels. In addition, these effects were accompanied by apoptosis of subG1-phase cells. It was revealed that co-treatment with ZOL plus IR resulted in augmented inhibition of cell invasion, over the simple additive effect for each treatment alone.

It has been reported that the peak concentration of ZOL in serum, which is maintained only for a few $\mathrm{h}$, is $1-3 \mu \mathrm{M}$ (29). This observation indicates that the optimal serum concentrations of ZOL may not be readily achieved for its antitumor activity. It is unlikely that ZOL directly induces apoptotic effects at primary sites of solid tumors. By contrast, patients with advanced disease states, including bone metastasis and bone marrow carcinomatosis, may benefit from ZOL, where ZOL would be able to (or at least partially) induce apoptosis in tumor cells (8-10). Thus, ZOL is currently being used to treat cancer, together with other anticancer drugs, including chemotherapeutic drugs, molecular targeted drugs and other biological agents (10-12). The addition of ZOL in cancer therapy not only results in synergistic anticancer effects with other drugs, but also lowers the toxicity effects caused by these drugs (10-12). Similarly, since the present study focused on the anticancer effects caused by combination with ZOL and IR, a relatively lower concentration of ZOL $(2 \mu \mathrm{M})$ was selected, according to the result from the MTT cytotoxicity assays (Fig. 1). This combination of ZOL plus IR did not expose cells to excessive drug toxicity and allowed the radiosensitizing effect of ZOL to be investigated. This was consistent with other previous studies (15-20), in which ZOL plus IR decreased the drug concentration and the amount of irradiation to make the combination safer than when ZOL or radiotherapy were used alone, with less side effects. According to the current study, treatment of cancer cells with a low concentration of ZOL $(2 \mu \mathrm{M})$, which can be achievable clinically, could enhance the radiotherapeutic effects. These results suggest that $\mathrm{ZOL}$ in combination with IR may be utilized in clinical use, particularly in patients with cancer.

Generally, tumor cells during late $\mathrm{S}$ and G2/M phases are the most sensitive to radiotherapy $(30,31)$. In the present study, flow cytometry indicated that the proportion of cells in the $\mathrm{S}$ and subG1 phases was increased following combined treatment with ZOL plus IR; however, ZOL used alone had no effect on the cell cycle. These data suggest that co-treatment with ZOL plus IR may lead to prolonged cell cycle progression and subsequent apoptosis. The present results are similar to the observations reported previously on other types of cancer cells (17-20). These findings suggest that the underlying mechanism of the radiosensitizing effect may involve not only prolongation of cell cycle progression but also induction of apoptosis. Notably, p53, a tumor-suppressor gene involved in numerous intracellular pathways triggered by IR exposure, is often disrupted in multiple cancers (32). The p53-independent apoptotic effect suggests that ZOL may serve as a promising tool to treat cancers, particularly those with radio or chemoresistance due to loss of p53 function $(25,33)$.
It has been reported that ZOL may induce cell-cycle prolongation by altering the expression of certain cyclins and their associated regulatory proteins $(13,24-26)$. The present study also revealed that co-treatment with ZOL plus IR elevated the expression levels of S- and M-phase cyclins, cyclin A and B, while downregulated the cyclin-dependent kinase inhibitor p $21^{\mathrm{CIP} 1}$, which may lead to cell cycle arrest between intra-S and $\mathrm{M}$ phases. Of note, the expression levels of cyclins D1 and $\mathrm{E}$, as well as $\mathrm{p} 27^{\mathrm{KIP} 1}$, were not significantly altered upon combined treatment. These results are in accordance, at least in part, with other cancers reported previously (13,24-26).

In the present study, it was also revealed that combined treatment with ZOL plus IR exhibited synergism rather than their individual use, as demonstrated by the anti-invasive effects against cancer cells. Thus, co-treatment with ZOL plus IR may be used to increase the anti-proliferative and anti-metastatic effects, and to decrease side effects and complications. These findings suggest that ZOL in combination with IR may be a promising therapy for cancer patients.

\section{Acknowledgements}

The authors thank Ms. Jiongyu Chen (Oncological Research Laboratory, Cancer Hospital of Shantou University Medical College, Shantou, China) for technical assistance. The present study was supported in part by the Science and Technology Planning Project of Henan Province, China (grant no. 142102310464, awarded to Y. You) and the Key Research Foundation of Higher Education of Henan Province, China (grant no. 15B320003).

\section{References}

1. You Y, Li H, Chen J, Qin X and Ran Y: Zoledronic acid reverses cisplatin resistance in nasopharyngeal carcinoma cells by activating the mitochondrial apoptotic pathway. Oncol Lett 13: 1840-1846, 2017.

2. Minsky BD, Pajak TF, Ginsberg RJ, Pisansky TM, Martenson J, Komaki R, Okawara G, Rosenthal SA and Kelsen DP: INT 0123 (radiation therapy oncology group 94-05) phase III trial of combined-modality therapy for esophageal cancer: High-dose versus standard-dose radiation therapy. J Clin Oncol 20: 1167-1174, 2002.

3. Yamashita S, Kondo M and Hashimoto S: Squamous cell carcinoma of the nasopharynx. An analysis of failure patterns after radiation therapy. Acta Radiol Oncol 24: 315-320, 1985.

4. Al-Sarraf M, LeBlanc M, Giri PG, Fu KK, Cooper J, Vuong T, Forastiere AA, Adams G, Sakr WA, Schuller DE and Ensley JF: Chemoradiotherapy versus radiotherapy in patients with advanced nasopharyngeal cancer: Phase III randomized Intergroup study 0099. J Clin Oncol 16: 1310-1317, 1998.

5. Mao YP, Zhou GQ, Liu LZ, Guo R, Sun Y, Li L, Lin AH, Zeng MS, Kang TB, Jia WH, et al: Comparison of radiological and clinical features of temporal lobe necrosis in nasopharyngeal carcinoma patients treated with 2D radiotherapy or intensity-modulated radiotherapy. Br J Cancer 110: 2633-2639, 2014.

6. Jemal A, Murray T, Ward E, Samuels A, Tiwari RC, Ghafoor A, Feuer EJ and Thun MJ: Cancer statistics, 2005. CA Cancer J Clin 55: 10-30, 2005.

7. Dunford JE, Thompson K, Coxon FP, Luckman SP, Hahn FM, Poulter CD, Ebetino FH and Rogers MJ: Structure-activity relationships for inhibition of farnesyl diphosphate synthase in vitro and inhibition of bone resorption in vivo by nitrogen-containing bisphosphonates. J Pharmacol Exp Ther 296: 235-242, 2001.

8. Yuasa T, Kimura S, Ashihara E, Habuchi T and Maekawa T: Zoledronic acid - a multiplicity of anti-cancer action. Curr Med Chem 14: 2126-2135, 2007.

9. Jantunen E: Bisphosphonate therapy in multiple myeloma: Past, present, future. Eur J Haematol 69: 257-264, 2002. 
10. Koto K, Murata H, Kimura S, Horie N, Matsui T, Nishigaki Y, Ryu K, Sakabe T, Itoi M, Ashihara E, et al: Zoledronic acid inhibits proliferation of human fibrosarcoma cells with induction of apoptosis, and shows combined effects with other anticancer agents. Oncol Rep 24: 233-239, 2010.

11. Zhao M, Tominaga Y, Ohuchida K, Mizumoto K, Cui L, Kozono S, Fujita H, Maeyama R, Toma H and Tanaka M: Significance of combination therapy of zoledronic acid and gemcitabine on pancreatic cancer. Cancer Sci 103: 58-66, 2012.

12. Matsumoto S, Kimura S, Segawa H, Kuroda J, Yuasa T, Sato K, Nogawa M, Tanaka F, Maekawa T and Wada H: Efficacy of the third-generation bisphosphonate, zoledronic acid alone and combined with anti-cancer agents against small cell lung cancer cell lines. Lung Cancer 47: 31-39, 2005.

13. Ge XY, Yang LQ, Jiang Y, Yang WW, Fu J and Li SL: Reactive oxygen species and autophagy associated apoptosis and limitation of clonogenic survival induced by zoledronic acid in salivary adenoid cystic carcinoma cell line SACC-83. PLoS One 9: e101207, 2014

14. Di Salvatore M, Orlandi A, Bagalà C, Quirino M, Cassano A, Astone A and Barone C: Anti-tumour and anti-angiogenetic effects of zoledronic acid on human non-small-cell lung cancer cell line. Cell Prolif 44: 139-146, 2011.

15. You Y, Liu J, Wang Z, Zhang Y, Ran Y, Guo X, Liu H and Wang H: The enhancement of radiosensitivity in human esophageal squamous cell carcinoma cells by zoledronic acid and its potential mechanism. Cytotechnology 66: 17-25, 2014.

16. Algur E, Macklis RM and Häfeli UO: Synergistic cytotoxic effects of zoledronic acid and radiation in human prostate cancer and myeloma cell lines. Int J Radiat Oncol Biol Phys 61: 535-542, 2005.

17. Ryu K, Murata H, Koto K, Horie N, Matsui T, Nishigaki Y, Sakabe T, Takeshita H, Itoi M, Kimura S, et al: Combined effects of bisphosphonate and radiation on osteosarcoma cells. Anticancer Res 30: 2713-2720, 2010.

18. Lopez Jornet P, Susana SC, Rosario TM and Alvaro PF Zoledronic acid and irradiation in oral squamous cell carcinoma. J Oral Pathol Med 44: 103-108, 2015.

19. Ural AU and Avcu F: Radiosensitizing effect of zoledronic acid in small cell lung cancer. Lung Cancer 50: 271-272, 2005.

20. Ural AU, Avcu F, Candir M, Guden M and Ozcan MA: In vitro synergistic cytoreductive effects of zoledronic acid and radiation on breast cancer cells. Breast Cancer Res 8: R52, 2006

21. You Y, Yang W, Qin X, Wang F, Li H, Lin C, Li W, Gu C, Zhang Y and Ran Y: ECRG4 acts as a tumor suppressor and as a determinant of chemotherapy resistance in human nasopharyngeal carcinoma. Cell Oncol (Dordr) 38: 205-214, 2015.

22. Chan SY, Choy KW, Tsao SW, Tao Q, Tang T, Chung GT and Lo KW: Authentication of nasopharyngeal carcinoma tumor lines. Int J Cancer 122: 2169-2171, 2008.
23. Ye F, Chen C, Qin J, Liu J and Zheng C: Genetic profiling reveals an alarming rate of cross-contamination among human cell lines used in China. FASEB J 29: 4268-4272, 2015.

24. You Y, Yang W, Wang Z, Zhu H, Li H, Lin C and Ran Y: Promoter hypermethylation contributes to the frequent suppression of the CDK10 gene in human nasopharyngeal carcinomas. Cell Oncol (Dordr) 36: 323-331, 2013

25. Kuroda J, Kimura S, Segawa H, Sato K, Matsumoto S, Nogawa M, Yuasa T, Kobayashi Y, Yoshikawa T, Ottmann OG and Maekawa T: p53-independent anti-tumor effects of the nitrogen-containing bisphosphonate zoledronic acid. Cancer Sci 95: 186-192, 2004.

26. Li YY, Chang JW, Liu YC, Wang CH, Chang HJ, Tsai MC, Su SP and Yeh KY: Zoledronic acid induces cell-cycle prolongation in murine lung cancer cells by perturbing cyclin and Ras expression. Anticancer Drugs 22: 89-98, 2011.

27. Mani J, Vallo S, Barth K, Makarević J, Juengel E, Bartsch G, Wiesner C, Haferkamp A and Blaheta RA: Zoledronic acid influences growth, migration and invasive activity of prostate cancer cells in vitro. Prostate Cancer Prostatic Dis 15: 250-255, 2012.

28. Li XY, Lin Y, Huang W, Hong CQ, Chen JY, You YJ and Li WB: Zoledronic acid inhibits proliferation and impairs migration and invasion through downregulating VEGF and MMPs expression in human nasopharyngeal carcinoma cells. Med Oncol 29: 714-720, 2013.

29. Skerjanec A, Berenson J, Hsu C, Major P, Miller WH Jr, Ravera C, Schran H, Seaman J and Waldmeier F: The pharmacokinetics and pharmacodynamics of zoledronic acid in cancer patients with varying degrees of renal function. J Clin Pharmacol 43: 154-162, 2003.

30. Sinclair WK: Cyclic x-ray responses in mammalian cells in vitro. Radiat Res 33: 620-643, 1968.

31. Milas L, Hunter NR, Mason KA, Kurdoglu B and Peters LJ: Enhancement of tumor radioresponse of a murine mammary carcinoma by paclitaxel. Cancer Res 54: 3506-3510, 1994.

32. Yip KW, Shi W, Pintilie M, Martin JD, Mocanu JD, Wong D, MacMillan C, Gullane P, O'Sullivan B, Bastianutto C and Liu FF: Prognostic significance of the Epstein-Barr virus, p53, Bcl-2, and survivin in nasopharyngeal cancer. Clin Cancer Res 12 : 5726-5732, 2006.

33. Ory B, Blanchard F, Battaglia S, Gouin F, Rédini F and Heymann D: Zoledronic acid activates the DNA S-phase checkpoint and induces osteosarcoma cell death characterized by apoptosis-inducing factor and endonuclease-G translocation independently of p53 and retinoblastoma status. Mol Pharmacol 71: 333-343, 2007. 